particular species conform to a definite structural pattern, but aberrant forms are not unusual and there is still hope (in the case of mouse leukaemia virus) that 'tails' are not entirely artefactual. A scheme of classification based on symmetry, nucleic acid type, presence of envelope, and site of assembly of virus in the cell does not result in any clearcut separation of oncogenic viruses from non-oncogenic viruses.

This volume maintains the high standard of this series. The summary of contents before each chapter is particularly helpful for rapidly obtaining information. The only adverse criticism is that there are a few spelling mistakes. I hope the word 'homograph' is not a new addition to transplantation terminology! F. C. Chesterman

\section{SOIL SCIENCE}

\section{Elements of Tropical Soil Science}

By Dr. T. Eden. Second edition. Pp. ix + 164. (London: Macmillan and Co., Ltd.; New York: St. Martin's Press, Inc., 1964.) 13s. 6d. net.

\section{Practical Soil Science}

(Israel Program for Scientific Translations.) By N. N. Nikol'skii. Translated by Rivka Nadel. Pp. v +240 . (Distributed by: Oldbourne Press, London; 1963.) $72 s$.

The Physical Chemisty and Mineralogy of Soils

By C. E. Marshall. Vol. 1: Soil Materials. Pp. ix +388 . (New York, London and Sydney: John Wiley and Sons, Ine., 1964.) $90 s$.

R. EDEN'S Elements of Tropical Soil Science is directed particularly to farmers and planters in the tropics rather than to the generality of students, but nevertheless for the greater part comprises chapters on the widely applicable principles of morphology, the physical and chemical properties of soils, and on manuring and the availability of nutrients. The chapters on erosion and the maintenance of soil fertility have a more specific direction to tropical circumstances, but for the rest tropical references are confined to illustrative examples. Because the author has lived his life in the East and in Africa these illustrations are usually very good indeed, as in his treatment of the soil catena and of laterization.

The book is descriptive, so that errors of technology (for example, the definition of the water table is wrong) have no catastrophic consequences.

Dr. Nikol'skii's Practical Soil Science is approved in the U.S.S.R. as a text for the faculties of agrochemistry, soil science and agronomy. Nearly three-fifths of the book is a laboratory manual for the quantitative chemical analysis of soil, and another fifth describes physical analyses. Only the remainder concerns itself with the field description and mapping of soil profiles, a subject which Russians have pioneered.

The chemical section is divided into chapters on the analysis of whole soil, including the determinations of organic matter, carbonates and mineral elements; on the determination of exchangeable cations and of the base exchange capacity; on soil acidity; and on the analysis of water soluble material. Every determination is described. in detail and the formulae for working out the results are written down. Some disorder is noticeable, matter being placed in the sections somewhat arbitrarily and occasionally in the wrong company. It is in the character of the book that in only one case is the agronomic significance of a determination discussed, and the reader is left to wonder just what is the agronomic relevance of a fusion analysis of whole soil. This part is a welcome addition to laboratory texts for students.

The physical analyses include measurements of soil density and volume weight, moisture content by straight- forward gravimetric methods, shrinkage, stability of aggregation, and mechanical analysis in some detail. The author follows the American usage in identifying, by definition, texture and mechanical composition, which is at best an impoverishment of the language and at worst a source of confusion. Selected soil states for the measurement of moisture content are rather arbitrary, and soil permeability is covered without mention of Darcy's law. All this is conventional descriptive soil physics which has little relation to the application of the laws of physics to soil.

The translation of the sections on soil morphology and mapping has evidently been difficult and some interpretation is still left to the reader. The elements of profile description are familiar enough, but here the wealth of illustrative examples drawn from a wide experience of soils representative of the great world groups is quite fascinating. The description of soil structure is very well illustrated, although not everyone would limit the definition of structure to the shapes and sizes of aggregates. If this part is more appropriate to a general textbook of pedology than to a practical manual, the balance is restored by the chapter on field survey procedure and mapping.

For more than thirty years Dr. Marshall has been one of the leading contributors to our understanding of the physical chemistry of colloidal materials in the soil. The Physical Chemistry and Mineralogy of Soils distils the essence of his experience of that field and its appearance is a notable event.

The various chapters summarize the basic physicochemical concepts and methods applicable to soil constituents; discuss in some detail the crystal structures of minerals which characterize the clay fraction and the coarser fractions; but necessarily are reduced to more empirical descriptions of organic matter. They go on to describe the molecular adsorption of gases and liquids, principally water; the electrochemistry of clays and the closely allied subjects of the exchange and fixation of ions from extraneous solutions; and conclude with a discussion of the electrokinetic and physical properties of cataphoresis, coagulation, viscosity and swelling.

Let it be said at once that this is not a course text-book Much of the groundwork is taken for granted or the reader is directed to the standard works. Rather little is worked out in detail and fully developed. This is essentially a coverage of a wide range of diverse kinds of experimental work described in just sufficient detail to enable the author to place each item in the general picture which emerges. The wealth of references makes this a source book and a launching pad for further researches.

It is Dr. Marshall's particular difficulty that he has to try to reconcile two concepts which are in some ways mutually incompatible. On the one hand the Stern and Gouy layers, which are at the foundations of modern analysis, are regions of non-uniform distributions of electric potential and ionic concentration. On the other hand, the conventional terminology of ionic activities, degree of dissociation, membrane potential, Donnan equilibrium and so on imply uniformity of these quantities. Success in his task is not aided by some hasty composition, as when he tells us that "the arithmetical average of the electrostatic potentials becomes the logarithmic average of the ionic activities'.

The outlines are again blurred late in the book when the author contrasts what he alleges to be a surface tension model of clay swelling with the Gouy layer picture. The latter does, of course, account physically for a swelling pressure, while the former proves to throw no light whatever on the mechanism of swelling.

These are small criticisms to put against the great service that the author has rendered in putting a little order into this heterogeneous field and in particular for reproducing for a wider public some truly magnificent electron photomicrographs.
E. C. ChILDS 